\title{
Immigration as a Commitment Device
}

\author{
Alexander Kemnitz* \\ University of Mannheim \\ Department of Economics \\ D-68131 Mannheim
}

October 2004

\begin{abstract}
This paper shows that the toleration of immigrants who are on average less skilled than natives can be part of a support-maximizing government policy, despite a general political bias in favor of the poor. We make this point in a simple model with redistributive unemployment insurance. Once wage contracts are binding, the government has an incentive to increase the unemployment benefit, leading to excessive unemployment. Affecting the political balance within the constituency, immigrants can serve as a commitment device against this time-inconsistency. We show that this possibility can be greatly promoted by restrictions on political naturalization.
\end{abstract}

JEL classifications: D72, F22, J68

Keywords: Immigration, Welfare State, Democracy, Time Inconsistency

*Tel: +49-621-1811798. Fax: +49-621-1813159. e-mail: kemnitz@econ.uni-mannheim.de. Thanks to Nick Ehrhart for helpful comments. 


\section{Introduction}

It is well known that the distributional implications of immigration can be harmful for substantial parts of the population of the receiving country, in particular in the presence of a welfare state. Being on average less skilled than natives, immigrants to such countries do not only depress market incomes but also welfare payments of the native poor. As shown by a number of authors, these adverse effects continue to prevail even after taking politico-economic repercussions into account, as these adjustments are either unsubstantial or even reinforcing (Mazza and van Winden, 1996, Kemnitz, 2002, Razin, Sadka and Swagel, 2002).

From a political economy perspective, this raises a puzzle. Given that the existence of substantial welfare programs is explained by the political influence of the poor, a policy harming this population group is unlikely to be implemented. It is therefore somewhat bewildering that immigration to the OECD remains substantial and the average education level of immigrants has even decreased in a number of countries. ${ }^{1}$ Although one can take immigration as an inevitable facet of globalization and/or driven by humanitarian motives, a closer investigation of the political compatibility of immigration and the welfare state seems legitimate. ${ }^{2}$

This paper argues that admitting immigrants who are on average less skilled than natives can be part of the policy of a support-maximizing government generally biased towards the low skilled. This possibility originates in a time-inconsistency problem on part of the government: once wage contracts are signed, politicians have an incentive to adjust the unemployment benefit in order to increase political popularity. Since this behavior ignores the ex ante effects on wage setting, unemployment is excessive. By affecting both the composition and the preferred policies of the politically active population, immigrants can serve as a commitment device against such immoderate ex post incentives. Particularly, the excessiveness of redistribution weakens the political resistance of the native low skilled by so much that the government finds it worthwhile to tolerate some migrants despite the existence of a welfare state due to the political power of the poor.

1 Between 1999 and 2000, immigration to the EU rose by 3.2\% (SOPEMI, 2003), with increases above $10 \%$ in The Netherlands, Finland, and France. Simultaneously, these countries experienced an increase in the share of foreigners having at most lower secondary education (SOPEMI, 2001, 2003; Table I.11.).

2 Working immigration varies significantly among countries from about none in Sweden to more than $50 \%$ in Portugal (SOPEMI, 2003; Chart I.2.). 
Obviously, this mechanism hinges on the premise that migrants curtail the political influence of the poor. We show that such an effect can be promoted by strict rules for political participation. For this purpose, we present a setting where the host follows a closed border policy if migrants enjoy the same political rights as natives. Limiting the franchise of the migrants, however, generates political support for their admission. As a consequence, the equilibrium immigration policy features the toleration of some migrants and limited naturalization. ${ }^{3}$

The combination of the government's interest to balance the interests of various social groups with a commitment problem on the decision on distorting transfers distinguishes this model from the existing literature on the political economy of immigration. Razin, Sadka and Swagel (2002) analyze low skilled immigration to an economy where the median voter decides on a demogrant transfer financed by proportional income taxation. With the decisive voter being a low skilled native, they find that immigration decreases the tax rate, a finding confirmed in a cross-country regression. As a consequence, the host country prefers a closed border policy. Mazza and van Winden (1996) and Kemnitz (2002) come to similar results in representative democracy models. Since immigration implies factor price changes antagonizing the redistribution engineered by the welfare state, both studies show that a government serving the interests of (low skilled) workers tolerates no immigration. However, government commitment is not an issue in either approaches: it is irrelevant in Mazza and van Winden (1996), considering lump sum transfers, while the government anticipates the labor market consequences of increasing unemployment insurance in Kemnitz (2002). Grether, de Melo and Müller (2001) show that low skilled natives may prefer low skilled immigration when all natives hold the same stock of another, fixed factor like physical capital. However, this result relies on full employment and breaks down once low skilled households own very little capital. Moreover, it is clearly at odds with existing evidence on individual attitudes towards immigration (ISSP, 1995). The present approach, in contrast, is able to reconcile immigrant admission with low skilled resistance.

The paper proceeds as follows. The next section presents the basic model and derives the labor market and welfare state effects of an exogenously given number of immigrants with exogenously given political power. Section 3 addresses the optimal immigration policy, that is, both the support-maximizing number and political integration of immigrants.

3 Indeed, only about $3-4 \%$ of foreign residents acquire the nationality of the host in most OECD countries per year. In 2000, Sweden and Portugal displayed the highest and lowest naturalization rates of about $9 \%$ and $0.5 \%$, respectively (SOPEMI, 2003; Chart I.18.). 


\section{The Model}

Consider an economy producing a single output good, composed of a large number of intermediate goods. Each intermediate is produced in a separate industry sector by atomistic firms employing high and low skilled labor $H$ and $L$, respectively. To simplify matters, all intermediates are perfect substitutes in producing the output good. Moreover, all firms possess the same Cobb-Douglas production function:

$$
Y=A H^{\alpha} L^{1-\alpha}
$$

with $\alpha \in(1 / 2,1]^{4}$

The native population comprises $N_{H}$ and $N_{L}$ high, respectively low skilled households. The absence of any scale effects in the model allows us to normalize the total size of the native population to unity and to express the native skill composition by the native skill ratio $h_{N}=N_{H} / N_{L}$.

For convenience, natives are assumed to be completely immobile, such that the economywide skill ratio before immigration equals $h_{N}$. However, after the immigration of $M$ households, of $M_{H}$ and $M_{L}$ are high respectively low skilled,the economy-wide skill ratio becomes:

$$
h=\frac{h_{N}+h_{M} M}{1+M}
$$

with $h_{M}=M_{H} / M_{L}$ denoting the immigrant skill ratio. Reflecting the stylized fact that immigration to OECD countries is predominately, but not entirely low skilled, we consider the case $h_{M}<h_{N}$, such that $\frac{d h}{d M}=M\left(h_{N}-h_{M}\right) /(1+M)^{2}<0$, but with $h_{M}>0 .{ }^{5}$ For simplicity, the supply of immigrants is unlimited.

As immigrants and natives of equal qualifications are assumed to be perfect substitutes in production, they face equal employment chances. While the high skilled become employed with certainty as that market is perfectly competitive, a low skilled's probability of not getting a job equals the low skilled unemployment rate:

4 The Cobb-Douglas technology is quite popular in the migration literature (Casarico and Devillanova, 2003) and is mostly used for convenience. For the empirically more relevant case of the elasticity of substitution between skills exceeding unity (Johnson, 1997), immigration would enjoy even stronger political support than in the present setup for it would decrease the low skilled unemployment rate for a given tax rate (Kemnitz, 2004).

5 According to SOPEMI (2003), the fraction of foreigners with at most lower secondary education exceeds the respective fraction of natives in 15 of 21 considered OECD countries. At the same time, the fraction of foreigners having received tertiary education exceeds the respective fraction of natives in 14 of these nations. However, this figure is likely to overstate effective foreign high skilled labor as many migrants work in less qualified occupations. 


$$
u=\frac{N_{L}+M_{L}-L}{N_{L}+M_{L}},
$$

where $L$ denotes total low skilled employment.

The government aims to maximize political support within the constituency. As elaborated by a number of studies (Lindbeck and Weibull, 1987, Grossman and Helpman, 1996), this is tantamount to maximizing a politically weighted sum of the utilities of all resident households, with the individual political weights comprising a variety of factors like the disposition to be a swing voter or the membership in special interest groups like trade unions, e.g.. In this section, we simply take these weights as exogenous and attend to the determinants of political influence in more detail in the next section. Normalizing the per capita weight of a high skilled native unity, a native low skilled worker has relative influence $\lambda_{L}$, whereas an unemployed low skilled native has the relative weight $\lambda_{L} \lambda_{U}$. In the following, $\lambda_{U} \geq 1$, that is, political importance is nondecreasing in the employment status. This feature introduces the 'single-mindedness hypothesis' of Mulligan and Sala-i-Martin (1999) to the political economy of unemployment insurance. This hypothesis presumes that every citizen has a more or less fixed amount of political resources to be allocated among various issues. Caring mostly about redistributive programs, nonworkers tend to have fewer special interests than workers caring about several countervailing issues due to different occupations and industry affiliations. This makes the unemployed ideologically more homogenous and endows them with superior political importance. While this hypothesis has been used exclusively in in the public pension context hitherto (see, e.g. Profeta, 2002), with the retired gaining superior influence, the extension towards unemployment insurance is natural.

With immigrants (if any) entering the country at stage 2, political decisions at stage 1 are guided by the preferences of the natives only. At stage 3, however, immigrants may affect politics. We denote the political importance of an immigrant, relative to a high skilled native, by $\mu_{H}, \mu_{L}$ and $\mu_{U}=\mu_{L} \lambda_{U}$, respectively. These influence parameters depend, among other things, on the rules for political naturalization determined at stage 1 , an issue addressed in the following section. ${ }^{6}$ For convenience, the single-mindedness

6 The theoretical literature suggests that the higher cultural diversity of migrants translates into a lower per capita weight. Mazza and van Winden (1996) consider the case where this diversity erodes the political influence of workers, such that $\mu_{L}$ decreases in $M$. Fuest and Thum (2001) make a similar argument with respect to trade union power. Since this may exert countervailing effects on the stage 1 attitude of low skilled natives, we consider the per capita weights to be independent of the number of migrants. From an empirical point of view, the importance of cultural diversity 
of the unemployed is symmetric, such that the relative political importance of an unemployed low skilled compared to an employed low skilled is the same for natives and immigrants. For further reference, let $h_{N} / \lambda_{L}\left(\mu_{H} h_{M} / \mu_{L}\right)$ denote the relative political influence of the native (immigrant) low skilled worker.

Terming the wages of skilled and unskilled workers $w_{H}$ and $w_{L}$ and assuming individual utility to be logarithmic in income, the government enjoys political support

$$
\begin{aligned}
S= & \left(N_{H}+\mu_{H} M_{H}\right) \log \left[(1-\tau) w_{H}\right] \\
& +\left(\lambda_{L} N_{L}+\mu_{L} M_{L}\right)\left((1-u) \log \left[(1-\tau) w_{L}\right]+u \log [b]\right),
\end{aligned}
$$

where $\tau$ is the tax rate and the government budget constraint $\left(N_{L}+M_{L}-L\right) b=$ $\tau\left(w_{H} H+w_{L} L\right)$ gives the unemployment benefit $b=\frac{\lambda_{U} \tau w_{L}(1-u)}{u(1-\alpha)}$.

With wages and employment being fixed, the maximization of (3) with respect to $\tau$ yields the first-order condition:

$$
T=-\frac{N_{H}+\mu_{H} M_{H}}{1-\tau}+\left(\lambda_{L} N_{L}+\mu_{L} M_{L}\right)\left[-\frac{1-u}{1-\tau}+\frac{\lambda_{U} u}{\tau}\right]=0 .
$$

All employed households deprecate unemployment insurance, whereas the jobless prefer a tax rate of unity. Because marginal utility is infinite for zero income, the equilibrium benefit is positive whenever some people are unemployed. Obviously, the generosity of the benefit increases in both the number and the per capita influence of the jobless.

At stage 2, unions dictate the low skilled wage at the sectoral level in the interest of their members. As usual in the literature (Schmidt et al., 1994, Fuest and Thum, 2000, 2001, Kemnitz, 2002,2004), macroeconomic repercussions of wage setting are ignored because each sector is small. In particular, union wage setting disregards the fact that the unemployment benefit increases in aggregate low skilled unemployment. ${ }^{7}$ As a consequence, each union maximizes

$$
U=(1-\pi) L \log \left[(1-\tau) w_{L}\right]+\left(N_{L}+M_{L}-(1-\pi) L\right) \log [\bar{w}],
$$

with respect to $w_{L}$, taking $\bar{w}$, the income of the workers not finding employment in the home sector as given. Denoting the fraction of jobs captured by outside applicants, $\pi$ is a measure of intersectoral labor turnover in the spirit of Layard et al. (1991).

is mitigated by the fact that migrants to most OECD countries stem predominately from one or two origin countries with at least one of the top four sending countries having a border to the respective receiving country (SOPEMI, 2003).

7 This is different with respect to lobbying at stage 3, where each union knows that a higher unemployment benefit at the economy-wide level requires a higher tax rate. Introducing strategic interactions between wage policies and social protection would make the analysis more cumbersome without affecting the subsequent results. 
Taking into account that firms hire workers according to the marginal productivity conditions, such that:

$$
\begin{aligned}
w_{H} & =\alpha A\left(N_{H}+M_{H}\right)^{\alpha-1} L^{1-\alpha} \\
L & =\left(\frac{w_{L}}{(1-\alpha) A}\right)^{-1 / \alpha}\left(N_{H}+M_{H}\right)
\end{aligned}
$$

where we have already used the fact that high skilled labor is fully employed, the first-order condition for the sectoral low skilled wage becomes:

$$
(1-\tau) w_{L}=e^{\alpha} \bar{w}
$$

where $\alpha$ is the negative inverse of the own wage elasticity of low skilled labor demand. Due to the Cobb-Douglas technology, this elasticity is constant and the net low skilled wage is a constant markup on the alternative wage $\bar{w}$.

In the aggregate, $N_{L}+M_{L}-(1-\pi) L$ low skilled workers do not get employed in the home sector and apply for jobs elsewhere. As there are $\pi L$ vacancies, the success probability is:

$$
\xi(u)=\frac{\pi L}{N_{L}+M_{L}-(1-\pi) L}=\frac{\pi(1-u)}{1-(1-\pi)(1-u)},
$$

with $\xi^{\prime}(u)<0, \xi(0)=1$ and $\xi(1)=0$. With the residual probability $1-\xi(u)$, workers rely on unemployment benefits, such that the alternative wage is:

$$
\bar{w}=\xi(u)(1-\tau) E w_{L}+(1-\xi(u)) b
$$

Considering the identity of all sectors and the government budget constraint gives the aggregate wage setting relation:

$$
W=(1-\tau)\left(1-e^{\alpha} \xi\right)-(1-\xi) e^{\alpha} \frac{\tau}{1-\alpha} \frac{1-u}{u}=0
$$

Hence, the labor market equilibrium is characterized by the compatibility of both wage setting and political restrictions.

Proposition 1. There exists at least one labor market equilibrium characterized by (4) and (8). Each equilibrium features low skilled unemployment and a positive unemployment benefit.

Proof. Both $W$ and $T$ are upward sloping in $(u, \tau)$-space. However, for $u=0, \tau=0$ according to $T$, whereas $u>0$ for $\tau=0$ according to $W$. For $u=1, T$ implies $\tau<1$ and $W \tau=1$. Therefore, both curves must intersect at least once. 
Both the wage setting and the political restriction exhibit a positive relation between the tax rate and the low skilled unemployment rate. The more individuals are unemployed, the higher is the political pressure for providing social protection, and the higher the unemployment benefit is, the higher are union wage demands. Equilibrium low skilled unemployment is positive because unions allow for some unemployment even in the absence of a welfare state: for $\tau=0$, full employment would lead to the equality of sectoral and alternative wage, which is inconsistent with a positive markup. However, unemployment is not exhaustive, for this would require a politically infeasible tax rate of unity. ${ }^{8}$

The system (4),(8) may feature multiple equilibria. In what follows, we assume that the economy is (and remains) in an equilibrium with the property $d \tau /\left.d u\right|_{W}>d \tau /\left.d u\right|_{T}$ and hence:

$$
D=\frac{\partial W}{\partial u} \frac{\partial T}{\partial \tau}-\frac{\partial T}{\partial u} \frac{\partial W}{\partial \tau}<0
$$

There is a double justification for this assumption. First, at least one equilibrium with the property (9) must exist, because $W$ must cross $T$ at least once from below in $(u, \tau)$-space. Second, an increase in the alternative wage due to a rise in $\pi$, increases low skilled unemployment if and only if (9) holds:

$$
\frac{d u}{d \pi}=\frac{-1}{D} \underbrace{\frac{\partial W}{\partial \pi}}_{(<0)} \underbrace{\frac{\partial T}{\partial \tau}}_{(<0)} .
$$

Obviously, immigration affects the government's incentives for redistribution at stage 3:

Proposition 2. Immigration increases (decreases) both the tax rate and the low skilled unemployment rate if and only if the relative political weight of the immigrant low skilled worker is higher (lower) than the relative political weight of the native low skilled worker.

$$
\operatorname{sign} \frac{d \tau}{d M}=\operatorname{sign} \frac{d u}{d M}=\operatorname{sign}\left[\frac{h_{N}}{\lambda_{L}}-\frac{\mu_{H}}{\mu_{L}} h_{M}\right]
$$

8 With a tax rate of unity, all high skilled would be left with zero net income without having the opportunity to escape into unemployment since employment contracts are binding. Hence, opposition against both $\tau=0$ and $\tau=1$ is infinitely high. 
Proof. Use Cramer's Rule to get:

$$
\begin{aligned}
\frac{d u}{d M} & =\frac{1}{D} \frac{\partial T}{\partial M} \frac{\partial W}{\partial \tau} \\
\frac{d \tau}{d M} & =\frac{-1}{D} \frac{\partial T}{\partial M} \frac{\partial W}{\partial u}
\end{aligned}
$$

Because $\frac{\partial W}{\partial \tau}<0$ and $\frac{\partial W}{\partial u}<0$, the impact of immigration is determined by the sign of:

$$
\frac{\partial T}{\partial M}=\frac{\mu_{L} h_{N}-\mu_{H} \lambda_{L} h_{M}}{\left(1+h_{M}\right)\left(\lambda_{L} N_{L}+\mu_{L} M\right)}
$$

Immigration shifts the government's decision towards the group gaining more relative power than before. When immigrants and natives are absolutely identical $\left(\mu_{H} / \mu_{L}=\right.$ $\left.1 / \lambda_{L}\right)$, only changes in population shares matter and immigration increases the low skilled unemployment rate unambiguously. However, this can be reversed if the high skilled immigrants have sufficiently more power.

\section{Immigration Policy}

At stage 1, the government decides on both the number and the political rights of immigrants. Being guided by the interests of the natives only, it anticipates correctly how such a policy affects the ex post incentives for redistribution.

It should be emphasized that native sentiments towards immigrants depend on a host of factors, including security concerns and ethnic and racial identity. However, a number of recent empirical studies conclude that individual attitudes are to a large extent shaped by economic factors (Bauer et al., 2001, Scheve and Slaughter, 2001, Mayda, 2003). In a cross-country study, Mayda (2003) finds that differences in actual policies can be explained by the skill composition of natives relative to immigrants. Hence, the policy results from the government maximizing support:

$$
S_{N}=N_{H} \log (1-\tau) w_{H}+\lambda_{L} N_{L}\left[(1-u) \log (1-\tau) w_{L}+u \log b\right]
$$

Regarding the number of immigrants for given political participation, we have the 
first-order condition:

$$
\begin{aligned}
\frac{\partial S_{N}}{\partial M}= & \frac{\partial U_{H}}{\partial M}+\lambda_{L} N_{L} \frac{\partial E U_{L}}{\partial M} \\
= & \frac{w_{H} N_{H}}{(1-\tau) w_{H}}\left[-\frac{d \tau}{d M} w_{H}+(1-\tau) \frac{d w_{H}}{d M}\right] \\
& +\frac{\lambda_{L} N_{L}(1-u)}{(1-\tau) w_{L}}\left[-\frac{d \tau}{d M} w_{L}+(1-\tau) \frac{d w_{L}}{d M}\right] \\
& +\lambda_{L} N_{L}\left[\frac{u}{\tau} \frac{d \tau}{d M}+\frac{u}{w_{L}} \frac{d w_{L}}{d M}-\frac{1}{1-u} \frac{d u}{d M}\right]-\lambda_{L} N_{L} \log \frac{(1-\tau) w_{L}}{b} \frac{d u}{d M},
\end{aligned}
$$

which by (4) can be transformed to:

$$
\begin{aligned}
\frac{\partial S_{N}}{\partial M}= & \frac{d \tau}{d M}\left[\frac{\mu_{H} M_{H}}{1-\tau}+\mu_{L} M_{L}\left[\frac{1-u}{1-\tau}-\frac{u}{\tau}\right]+\frac{\left(1-\lambda_{U}\right) \mu_{L} N_{L}}{\tau}\right] \\
& +\frac{d u}{d M}\left[\frac{(\alpha-1)\left(N_{H}+\lambda_{L} N_{L}\right)}{1-u}-\log \frac{(1-\tau) w_{L}}{b}\right] \\
& +\frac{d h}{d M} \frac{(\alpha-1) N_{H}+\alpha \lambda_{L} N_{L}}{h} .
\end{aligned}
$$

The number of immigrants admitted for given political rights results from the interplay of three effects: a tax effect, an unemployment effect and a skill ratio effect. The latter effect describes how a change in the skill ratio, holding $\tau$ and $u$ constant, translates into political support. Straightforward calculations show that this effect is negative if and only if:

$$
\frac{\lambda_{L}}{h_{N}}>\frac{1-\alpha}{\alpha}
$$

This condition is easy to interpret. As defined above, $\lambda_{L} / h_{N}$ is the political weight of the native low skilled relative to the native high skilled. $(1-\alpha) / \alpha$, however, is the ratio of low and high skilled earnings before redistribution $w_{H} H / w_{L} L$, which measures the relative economic weight of the low skilled. Whenever (14) holds, we call the political process biased towards the low skilled, because a lump sum transfer from the high skilled to the low skilled increases political support (Mazza and van Winden, 1996). ${ }^{9}$

Proposition 3. The host country tolerates some immigration, when the relative political weight of the native low skilled exceeds the relative political weight of the immigrant low skilled and the political process is not too biased towards the low skilled.

9 To be precise, Mazza and van Winden (1996) derive this effect in the context of capital and labor. In our setting, the respective problem is $\max _{T} N_{H} \log \left(w_{H}-T\right)+\lambda_{L} N_{L} \log \left(w_{L}+N_{H} / N_{L} T\right)$ with the first order condition $-1 /\left(w_{H}-T\right)+\lambda_{L} /\left(w_{L}+N_{H} / N_{L} T\right)=0$. Hence, the optimal transfer is positive whenever (14) is fulfilled. 
Proof. For $M=0,(13)$ reduces to

$$
\begin{aligned}
\left.\frac{\partial S_{N}}{\partial M}\right|_{M=0}= & \frac{\left(1-\lambda_{U}\right) \mu_{L} N_{L}}{\tau} \frac{d \tau}{d M}+\frac{d u}{d M}\left[\frac{(\alpha-1)\left(N_{H}+\lambda_{L} N_{L}\right)}{1-u}-\log \frac{(1-\tau) w_{L}}{b}\right] \\
& +\frac{d h}{d M} \frac{(\alpha-1) N_{H}+\alpha \lambda_{L} N_{L}}{h}
\end{aligned}
$$

With a policy bias in favor of the low skilled, the skill ratio effect is unambiguously negative. However, the unemployment effect is positive for the first marginal immigrant. This holds because the lack of commitment renders a decrease of $u$ beneficial for both high and low skilled natives. Additionally, the tax rate effect is positive, because the unemployed enjoy inadequate political influence at stage 3 , evaluated from the perspective of stage 1 . Capturing the beneficial effects of immigration mitigating the government commitment problem, these two effects dominate a positive, but moderate political bias towards the low skilled. Hence, immigration is compatible with a political predominance of the low skilled. This result stands in sharp contrast to the findings under full employment (Mazza and van Winden (1996), Result 2) and unemployment without commitment problems (Kemnitz, 2002).

Moreover, marginal immigration can even be tolerated although the expected utility of the native low skilled:

$$
\frac{\partial E U_{L}}{\partial M}=\left[-\frac{1-u}{1-\tau}+\frac{u}{\tau}\right] \frac{d \tau}{d M}+-\left[\frac{\alpha-1}{1-u}+\log \frac{(1-\tau) w_{L}}{b}\right] \frac{d u}{d M}+\frac{d h}{d M} \frac{\alpha}{h}
$$

decreases. This is possible because the distortions caused by the lack of commitment soften low skilled resistance compared to a reduction of a lump sum transfer. Formally, $\frac{\partial E U_{L}}{\partial M}<0$ according to (16) does not contradict (15) being positive.

For a strictly positive number of immigrants, the sign of the tax effect is ambiguous. Any migrant influence on $\tau$ leads to a divergence of the stage 3 tax rate from the one maximizing native support at stage 1 , controlling for single-mindedness and the effects on $u$ and $h$, captured by the unemployment and skill ratio effects. In connection with a possible nonnegativity of $\frac{d \tau}{d M}$, this may lead to $\frac{\partial^{2} S_{N}}{\partial M^{2}}>0$. Therefore, Proposition 3 provides only a sufficient condition for immigrant admittance. However, we have the following

Corrolary. If the host country admits a positive, but finite number of immigrants in equilibrium, immigration decreases the tax rate and is unambiguously immoderate from the native low skilled point of view. 
An optimal finite number of immigrants balances the political gains and losses of increasing $M$, such that (13) is zero. Because the high skilled are unambiguous winners, the low skilled must be harmed by such immigration. This is concordant with the results of the International Social Survey Programme (ISSP, 1995), according to which a majority of natives prefers a reduction of immigration in 15 out of 22 considered countries and there is no majority to increase it in the other countries. Moreover, the unemployment effect must be positive in such an equilibrium, which implies $\frac{d \tau}{d M}<0$ by Proposition 2. Because this holds for all $M$, the tax rate must be lower than with closed borders, as observed empirically by Razin, Sadka and Swagel (2002).

Proposition 3 highlights the dependance of immigrant toleration on the distribution of their political activities. One obvious constellation for toleration would be the immigration of politically apathetic low skilled and high skilled political activists. We would like to focus on more plausible situations by stressing the connection between relative political weights and the rules for political naturalization. In this context, it is important to recognize that the government can regulate some sources of political influence like the franchise, while others like joining demonstrations or interest groups are very hard to impede. For the sake of concreteness, we assume that an immigrant's political importance depends on his interest group activities and his voting rights with the host government having the option to limit the latter. ${ }^{10}$

We will now show that the manipulation of voting rights can create an original support for immigration, which would not exist for full political naturalization. To make this point, let a low skilled native have the relative political influence $\lambda_{L}=\left(v_{L}+\Lambda_{L}\right) /\left(v_{H}+\right.$ $\left.\Lambda_{H}\right)$, where $\Lambda_{L}$ is the per capita influence of his pressure group and the voting influence is $v_{L}$. While the high and the low skilled have equal voting influence $v_{H}=v_{L}=v$, the per capita lobbying weight of a high skilled exceeds the per capita weight of a low skilled: $\Lambda_{H}>\Lambda_{L}$, such that $\lambda_{L}<1$. Such a constellation is absolutely compatible with a political bias towards the low skilled: Although a single high skilled is more important than a single low skilled, the low skilled as a whole can have more influence. Whenever $h_{N}>1 / \lambda_{L},(14)$ holds for all $\alpha \in[1 / 2,1)$.

At stage 3, his single-mindedness provides an unemployed with higher political weight than an employed low skilled. For convenience, we assume that this higher homogeneity

10 Of course, immigrants may use demonstrations and lobbying to fight for more political rights. In that sense, the government would find itself trapped in additional commitment problem as it may be induced to alter the announced naturalization policy. We do not model this problem here. However, one can consider the political weights presented below as a reduced form incorporating these repercussions. 
affects voting and interest group behavior equally, such that $\lambda_{U}=\phi>1$.

Except for voting rights, immigrants and natives of the same type are identical. Letting $\omega \in[0,1]$ denote the fraction of immigrants not receiving the franchise implies the relative weights:

$$
\begin{aligned}
\mu_{H} & =\frac{(1-\omega) v+\Lambda_{H}}{v+\Lambda_{H}}, \\
\mu_{L} & =\frac{(1-\omega) v+\Lambda_{L}}{v+\Lambda_{H}}, \\
\mu_{U} & =\phi \mu_{L} .
\end{aligned}
$$

In accordance with fundamental equity considerations, franchise restrictions can not be differentiated according to skills, but must affect all immigrants equally.

Proposition 4. For any positive number of immigrants, a limitation of voting rights decreases both the tax and the low skilled unemployment rate.

Proof. Because of

$$
\begin{aligned}
& \frac{d u}{d \omega}=\underbrace{\frac{1}{D} \frac{\partial W}{\partial \tau}}_{(>0)} \frac{\partial T}{\partial \omega} \\
& \frac{d \tau}{d \omega}=\underbrace{\frac{-1}{D} \frac{\partial W}{\partial u}}_{(>0)} \frac{\partial T}{\partial \omega},
\end{aligned}
$$

the sign of

$$
\frac{\partial T}{\partial \omega}=\frac{M_{H}}{v+\Lambda_{H}}-\frac{M_{L}}{v+\Lambda_{H}}\left[-(1-u)+\frac{v u(1-\tau)}{\tau}\right]
$$

is decisive for the effects on $\tau$ and $u$. Using (4) yields

$$
\frac{\partial T}{\partial \omega}=\frac{M_{L}}{\left(1+\Lambda_{H}\right)\left(\lambda_{L} N_{L}+\mu_{L} M_{L}\right)}\left[N_{L}\left(h_{M} \lambda_{L}-h_{N}\right)+M_{H}\left(\mu_{L}-\mu_{H}\right)\right] .
$$

Due to $\Lambda_{H}>\Lambda_{L}$, this expression is negative iff $M>0$.

Naturally, a restriction of immigrant voting rights is effective only when some immigrants enter. If this is the case, increasing $\omega$ has two effects: First, the government cares more for the skill group losing relatively less voters. Second, the importance of interest group activities increases. Both effects shift political power towards the high skilled, a finding that reflects in the reaction of native support at stage 1 :

$$
\begin{aligned}
\frac{\partial S_{N}}{\partial \omega}= & \frac{d \tau}{d \omega}\left[\frac{\mu_{H} M_{H}}{1-\tau}+\mu_{L} M_{L}\left[\frac{1-u}{1-\tau}-\frac{u}{\tau}\right]+\frac{\left(1-\lambda_{U}\right) \mu_{L} u N_{L}}{\tau}\right] \\
& +\frac{d u}{d \omega}\left[\frac{N_{H}}{w_{H}} \frac{\partial w_{H}}{\partial u}+\lambda_{L} N_{L} \frac{(1-u)}{w_{L}} \frac{d w_{L}}{d u}+\frac{u}{b} \frac{d b}{d u}\right]-\lambda_{L} N_{L} \frac{d u}{d \omega} \log \frac{(1-\tau) w_{L}}{b} .
\end{aligned}
$$


This expression shows that for not too high levels of immigration, there is unambiguous support for immigrant franchise restrictions: provided that $M$ is low enough to render the term in square brackets in the first line of (20) negative, $\frac{\partial S_{N}}{\partial \omega}>0$. However, the support-maximizing immigration policy contains provisions for both $M$ and $\omega$, with immigrant admissions depending negatively on immigrant franchise, and immigrant franchise depending negatively on the number of immigrants.

Proposition 5. The government pursues either a closed border policy or admits some immigrants, restricting their political rights. The latter option is chosen when both the immigrant skill ratio and the political bias towards the low skilled are not too low. In the absence of voting right restrictions, immigrants are never admitted.

Proof. Let $S_{N}(M, \omega)$ denote the political support attained by immigration policy $(M, \omega)$. Consider the case $h_{M}=h_{N}$ and $h_{N} /$. Since $S_{N}(0,0)=S_{N}\left(0, \omega^{\prime}\right)$ for all $\omega^{\prime}>0$ and $\frac{\partial S_{N}\left(0, \omega^{\prime}\right)}{\partial M}>0$, support is maximized by some positive $M$ and $\omega$. By continuity, the same argument must hold when immigration diminishes the skill ratio a bit and/or the low skilled have some political advantage.

This proposition shows that the host's ability to restrict immigrants' political rights can be a prerequisite for their admission. In the case of skill-neutral immigration $h_{M}=h_{N}$ with full political integration $(\omega=0)$, the host is indifferent with respect to $M$. However, admitting some immigrants and restricting their voting rights shifts political power to the high skilled with the simultaneous alleviation of the commitment problem increasing overall political support. Because political support is continuous in both $M$ and $\omega$, the same reasoning applies if immigrants are somewhat less skilled than the average native and/or there is some political bias towards the low skilled. Otherwise, the government finds it optimal to follow a closed-border policy.

\section{Conclusion}

This paper has presented a rationale why a government inclined to serve the interests of the poor might tolerate immigration although this harms the native low skilled in equilibrium. The argument rests on the government being trapped in a time inconsistency problem with respect to the unemployment benefit. Immigrants affect the politicoeconomic conditions and may therefore mitigate the lack of government commitment. The removal of the labor market inefficiency weakens the resistance of the native low skilled, relative to a situation where commitment plays no role. As franchise restric- 
tions can be used as a tool to create the desired political effect, the main implications of the model are consistent with a number of empirical observations: immigration is accompanied by low skilled resistance, it leads to a reduction of the tax rate and few immigrants are naturalized.

One natural way to extend the analysis would be to allow for skill requirements. In the present model, the constant-returns-to-scale technology makes any policy admitting both skill types equivalent to a policy tolerating a respective number of just one skill type. Hence the decision is whether to allow only low or only high skilled individuals. Since the presence of each low skilled increases the ex post incentive for redistribution while each high skilled reduces it, the optimal immigration policy will admit only the latter. However, it would then not be optimal anymore to curtail the political rights of immigrants.

Due to the similarity of political support to a utilitarian welfare function, it is tempting to conclude that this reasoning could also work with a benevolent government maximizing the sum of resident utilities. However, this turns out not to be true: When all individuals have equal weight, immigration is bound to tilt political power towards the low skilled, aggravating the commitment problem. Therefore, our argument in favor of immigration is confined to the politico-economic framework. 


\section{References}

Bauer, T. K., Lofstrom, M. and K. F. Zimmermann (2001): Immigration Policy, Assimilation of Immigrants and Natives' Sentiments towards Immigrants: Evidence from 12 OECD-Countries, Swedish Economic Policy Review 7, 11-53.

Casarico, A. and Devillanova, C. (2003): Social Security and Migration with Endogenous Skill Upgrading, Journal of Public Economics 87, 773-797.

Fuest, C. and Thum, M. (2001): Immigration and Skill Formation in Unionized Labor Markets, European Journal of Political Economy 17, 557-573.

Fuest, C. and Thum, M. (2000): Welfare Effects of Immigration in a Dual Labor Market, Regional Science and Urban Economics 30, 551-563.

Grether, J.-M., de Melo, J. and T. Müller (2001): The Political Economy of International Migration in a Ricardo-Viner Model, in Djajic, S. (ed.) International Migration: Trends, Policy and Impact, Routledge.

Grossman, G. and E. Helpman (1996): Electoral Politics and Special Interest Groups. Review of Economic Studies 63: 265-286.

ISSP (1995): National-identity Data Set. International Social Survey Programme.

Johnson, G. (1997): Changes in Earnings Inequality: the Role of Demand Shifts, Journal of Economic Perspectives 11, 41-54.

Kemnitz, A. (2004): Unemployment, Technology and the Welfare Effects of Immigration, mimeo.

Kemnitz, A. (2002): On the Political Economy of Low Skilled Immigration and the Welfare State, International Tax and Public Finance 9, 423-434

Layard, R., Nickell, S. and R. Jackman (1991): Unemployment. Macroeconomic Performance and the Labour Market, Oxford University Press.

Lindbeck, A. and Weibull, J. W. (1987): Balanced-Budget Redistribution as the Outcome of Political Competition, Public Choice 54, 273-297.

Mayda, A. M. (2003): Who is Against Immigration? A Cross-Country Investigation of Individual Attitudes toward Immigrants, IZA Discussion Paper 1115.

Mazza, I. and F. van Winden (1996): A Political Economic Analysis of Labor Migration and Income Redistribution. Public Choice 88: 333-363.

Mulligan, C. B. and X. Sala-i-Martin (1999): Gerontocracy, Retirement and Social 
Security, NBER Working Paper 7117.

SOPEMI (2001): Trends in International Migration, OECD, Paris.

SOPEMI (2003): Trends in International Migration, OECD, Paris.

Profeta, P. (2002): Retirement and Social Security in a Probabilistic Voting Model, International Tax and Public Finance 9, 331- 348.

Razin, A., Sadka, E. and Swagel, P. (2002): Tax Burden and Migration: a Political Economy Theory and Evidence, Journal of Public Economics 85, 167-190.

Scheve, K.F. and M. J. Slaughter (2001): Labor Market Competition and Individual Preferences over Immigration Policy, Review of Economics and Statistics 83, 133-145.

Schmidt, C. M., Stilz, A. and Zimmermann, K.F. (1994): Mass Migration, Unions, and Government Intervention, Journal of Public Economics 55, 185-201. 